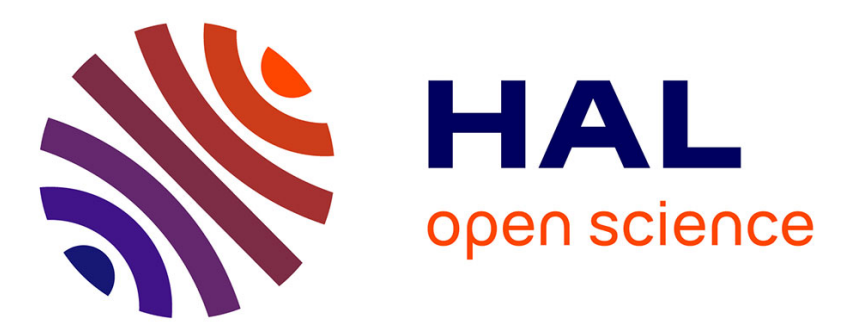

\title{
Reinforced sol-gel thermal barrier coatings and their cyclic oxidation life
}

Lisa Pin, Florence Ansart, Jean-Pierre Bonino, Yannick Le Maoult, Vanessa Vidal, Philippe Lours

\section{- To cite this version:}

Lisa Pin, Florence Ansart, Jean-Pierre Bonino, Yannick Le Maoult, Vanessa Vidal, et al.. Reinforced sol-gel thermal barrier coatings and their cyclic oxidation life. Journal of the European Ceramic Society, 2013, vol. 33, pp. 269-276. 10.1016/j.jeurceramsoc.2012.07.037 . hal-00836837

\section{HAL Id: hal-00836837 https://hal.science/hal-00836837}

Submitted on 21 Jun 2013

HAL is a multi-disciplinary open access archive for the deposit and dissemination of scientific research documents, whether they are published or not. The documents may come from teaching and research institutions in France or abroad, or from public or private research centers.
L'archive ouverte pluridisciplinaire HAL, est destinée au dépôt et à la diffusion de documents scientifiques de niveau recherche, publiés ou non, émanant des établissements d'enseignement et de recherche français ou étrangers, des laboratoires publics ou privés. 


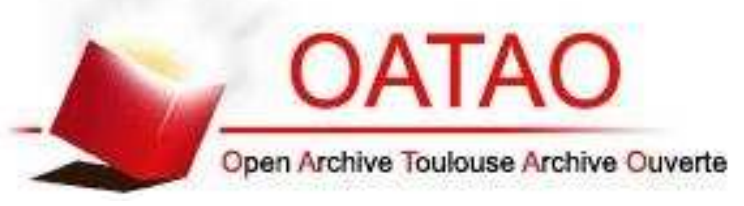

\section{Open Archive Toulouse Archive Ouverte (OATAO)}

OATAO is an open access repository that collects the work of Toulouse researchers and makes it freely available over the web where possible.

This is an author-deposited version published in: http://oatao.univ-toulouse.fr/ Eprints ID: 8733

To link to this article: DOI:10.1016/j.jeurceramsoc.2012.07.037

Official URL: http://dx.doi.org/10.1016/j.jeurceramsoc.2012.07.037

\section{To cite this version:}

Pin, Lisa and Ansart, Florence and Bonino, Jean-Pierre and Le Maoult, Yannick and Vidal, Vanessa and Lours, Philippe Reinforced sol-gel thermal barrier coatings and their cyclic oxidation life. (2013) Journal of the European Ceramic Society, vol. 33 (n²). pp. 269-276. ISSN 0955-2219

Any correspondence concerning this service should be sent to the repository administrator: staff-oatao@inp-toulouse.fr 


\title{
Reinforced sol- gethermal barrier coatings and their cyclic oxidation life
}

\author{
Lisa Pin ${ }^{\mathrm{a}, \mathrm{b}, *}$, Florence Ansart ${ }^{\mathrm{a}}$, Jean-Pierre Bonino ${ }^{\mathrm{a}}$, Yannick Le Maoult ${ }^{\mathrm{b}}$, \\ Vanessa Vidal ${ }^{\mathrm{b}}$, Philippe Lours ${ }^{\mathrm{b}}$ \\ ${ }^{\text {a }}$ University of Toulouse, UPS- INP- CNRSL, nstitut Carnot CIRIMAT, 118 Route de Narbonne, 31062 Toulouse Cedex 09, France \\ ${ }^{\mathrm{b}}$ University of Toulouse, Mines Albi-Institut Clément Ader, Campus Jarlard, F- 81013Albi Cedex 09, France
}

\begin{abstract}
Cyclic oxidation life enhancement of sol- gelthermal barrier coatings is obtained via the reinforcement of the controlled micro-crack network that forms during the initial sintering of the deposit. Two different sol- gelmethods are used to fill in the process-induced cracks, namely dipcoating and spray-coating. Filling parameters, for instance the number of passes or the viscosity of the sol are adjusted, using various techniques such as profilometry and microstructural analysis, to optimise crack filling. Cyclic oxidation tests are implemented at both $1100^{\circ} \mathrm{C}$ and $1150{ }^{\circ} \mathrm{C}$ to investigate the efficiency of the various reinforcement procedures developed and address the influence of the specific microstructure on the oxidation behaviour.
\end{abstract}

Keywords: Sol- gel@xidation; Reinforcement; Thermal barrier coating

\section{Introduction}

Improving turbojet engine performances requires to continuously increase the turbine inlet temperature. Nickel base superalloys, main materials used for the application, show superior creep and fatigue strength. However, superalloy turbine blades cannot sustain the high temperature imposed to modern engines without thermal protection and internal cooling. Thermal barrier coatings (TBCs) are deposited on hollow turbine blades in order to establish a thermal gradient prone to protect against the detrimental effects of long-term high temperature exposure. Thicker TBCs are also beneficially used to coat and thermally insulate the internal parts of the combustion chambers. Currently, TBCs - consisted of yttria-stabilised- zirconia (YSZ) - are manufactured using the so-called Electron Beam - Physical Vapour Deposition (EB-PVD), typically for turbine blades, or Plasma Spraying (PS), for combustion chambers. The thermal and mechanical properties of TBCs strongly depend on their

\footnotetext{
* Corresponding author at: University of Toulouse, UPS-INP-CNRS, Institut Carnot CIRIMAT, 118 Route de Narbonne, 31062 Toulouse Cedex 09, France. Tel.: +33 5615562 85; fax: +33 561556163 .

E- mailaddress: pin@chimie.ups-tlse.fr (L. Pin).
}

microstructure that straightforwardly results from the deposition process. EB-PVD coatings exhibit columnar microstructure where the presence of elongated grains and grain boundaries normal to the substrate surface allows a convenient accommodation of in-service lateral thermomechanical stresses and related strains. However, the thermal conductivity of EB-PVD coatings is not fully optimised as the presence of columnar porosities favours extensive heat transfer between the outer surface of the multi-material system and the superalloy substrate. Nevertheless some works aiming at adjusting the chemical composition ${ }^{1-4}$ and the microstructure of elongated grains ${ }^{1}$ allow to improve the insulation properties of such EB-PVD coatings. For PS coating, the typical microstructure is highly lamellar, resulting in both a lower thermal conductivity as the porosity is distributed perpendicular to the heat flux, and a lower ability to accommodate lateral thermomechanical stresses. Various additional ways to synthesize TBCs have been proposed in the literature, based on soft chemical processing. ${ }^{5-7}$ In this paper, a novel method for depositing and reinforcing TBCs, is investigated. Derived from the sol- gelroute, it includes either dip-coating, for the initial deposition and the post-processing reinforcement of the TBCs, or spray-coating, used after dip-coating, for the post-processing reinforcement of the TBCs only. Contrary to other processes, sol- gelTBCs show a specific isotropic microstructure with 
randomly distributed porosities. Properties and induced characteristics are very different compared to those of EB-PVD and PS coatings. This should result in an attractive compromise between thermal conductivity and mechanical strength. In a previous paper, ${ }^{8}$ the mechanisms responsible for the damage of sol- gelcoatings subject to cyclic oxidation was identified and discussed as a function of the oxidation temperature and the TBC thickness. Initially, the degradation of sol- geTCB proceeds through the formation of a regular crack network occurring, either during the post-deposition thoroughly controlled by thermal treatment or during the very first cycles of oxidation, in both cases as the result of the thermally-activated sintering of the zirconia deposit. This network can further develop itself during the cumulative oxidation cycles promoting the enlargement and the coalescence of cracks that finally lets appear individual TBC cells prone to spall off under the effect of the cyclic thermomechanical stresses. In order to improve the durability of sol- gelcoatings upon oxidation, it is proposed to control and stabilize the process-induced crack network by filling the cracks with fresh material brought either by supplementary dipcoating passes $^{9}$ or additional spray-coating passes. By providing an appropriate adjustment and control of the process, it has been shown that the crack filling by dip-coating significantly improves the cyclic oxidation behaviour of the $\mathrm{TBCs}^{9}$ through an overall reinforcement of the barrier resulting from an optimised mechanical pegging.

The present paper investigates (i) the feasibility of filling cracks using spray-coating and the principal difference with crack filling by dip-coating, (ii) the resulting characteristics of the microstructure and macrostructure developped and (iii) the durability of spray-coated reinforced TBCs during cyclic oxidation at $1100{ }^{\circ} \mathrm{C}$ and $1150{ }^{\circ} \mathrm{C}$. The overall performances of spray-filled and dip-filled reinforced TBCs are compared.

\section{Experimental}

\subsection{Synthesis of sol-gel thermal barrier}

AM1 superalloys substrates are initially coated with NiPtAl bond coat to enhance TBC adhesion. The substrate is then grit-blasted at 2.5 bars during $10 \mathrm{~s}$ with corundom particles. To process TBCs by sol- getoute, precursor YSZ sol with a composition of $9.7 \mathrm{~mol} \%$ yttria, is synthesized from zirconium (IV) propoxide $\mathrm{Zr}(\mathrm{OPr})_{4}$ (Aldrich) and yttrium (III) nitrate hexahydrate (Acros Organics). ${ }^{10}$ Acetylacetone (AcAc) is used as complexing agent to reduce the hydrolysis rate of zirconium alkoxide, ${ }^{7}$ and the solvent is the 1-propanol. Volume ratios between $\mathrm{AcAc}$ and $\mathrm{Zr}(\mathrm{OPr})_{4}$ and between $\mathrm{H}_{2} \mathrm{O}$ and $\mathrm{Zr}(\mathrm{OPr})_{4}$ are respectively 0.8 and 9.5. Zirconium concentration is kept constant at $0.5 \mathrm{~mol} \mathrm{~L}^{-1}$. Such a sol of YSZ is used to produce YSZ powder, obtained after supercritic drying of the propanol used as solvent. ${ }^{11}$ Following this step, an aerogel is first obtained. Ultimately, the powder is heat treated at $700{ }^{\circ} \mathrm{C}$. YSZ powders are dispersed into a slurry composed of the starting sol $(9.7 \mathrm{~mol} \%$ $\mathrm{YO}_{1.5}$ ) loaded with $40 \mathrm{wt} . \%$ of powder directly coming from the supercritic drying described above. Then, superalloy substrates are dipped into the slurry and withdrawn at a controlled

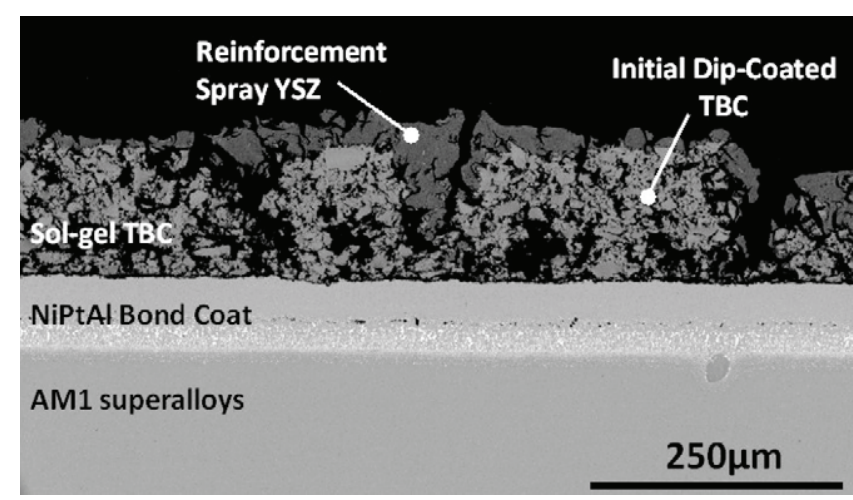

Fig. 1. SEM cross-section micrograph of a sol- gethermal barrier coating.

rate $(250 \mathrm{~mm} / \mathrm{min})$ to shape the coatings. After each dipping, the layer is drying at $50{ }^{\circ} \mathrm{C}$ during $5 \mathrm{~min}$. These operations are repeated until the required $\mathrm{TBC}$ thickness is reached. Processed specimens are sintered at $1100{ }^{\circ} \mathrm{C}$ during $2 \mathrm{~h}$ using heating and cooling rates of $100^{\circ} \mathrm{C} / \mathrm{h}$, to promote the formation of the initial crack network and somewhat stabilize the overall structure of the barrier by releasing residual sintering stresses. Subsequently, specimens with controlled cracks are reinforced using additional filling zirconia brought up inside crack grooves by either dip or spray-coating.

\subsection{Filling process}

The suspensions used for sol- gelfilling are composed of a commercial YSZ powder (TOSOH 8Y), in 1-propanol solvent. YSZ commercial powders are dispersed into a slurry composed of the starting sol $\left(9.7 \mathrm{~mol} \% \mathrm{YO}_{1.5}\right)$ loaded with 10 or $20 \mathrm{wt} . \%$ of this well dispersed and monodispersed powder (size of elementary particles around $30 \mathrm{~nm}$ ). Two different methods are used to fill in cracks: dip-coating and spray-coating. Dip-coating method consists in successively dipping and withdrawing at constant speed the substrate out of a slurry. Spray-coating consists in spraying the slurry from the top side of specimens, thus allowing the control of both the pressure and the displacement rate of the spray nozzle. Between each pass, the coating is drying at $50{ }^{\circ} \mathrm{C}$ during $5 \mathrm{~min}$. When, reinforcement synthesize process is finished, finally the specimens are heat treated at $1100^{\circ} \mathrm{C}$ during $2 \mathrm{~h}$, using heating and cooling rates of $50{ }^{\circ} \mathrm{C} / \mathrm{h}$. A cross-section micrograph of a sol- geldeposit, filled with additional spraycoating is presented in Fig. 1. As powders used respectively for the initial dip-coating and for the spray filling have different densities, the contrast between the YSZ brought by spray filling and the layer of initially dip-coated YSZ is clearly observed. Table 1 gives the details of the various specimens investigated in terms of filling process employed (DC: dip-coating and SC: spray-coating), numbers of passes and weight percent of powder in the slurry.

In order to characterize surface topography of the asprocessed as well as the filled samples and to quantify both the depth and the width of cracks, confocal interferometry microscopy, with a dynamic range of $15 \mathrm{~nm}-35 \mathrm{pum}$ is used. In 
Table 1

Reference and process parameters for the investigated specimens.

\begin{tabular}{lll}
\hline $\begin{array}{l}\text { Sample } \\
\text { reference }\end{array}$ & $\begin{array}{l}\text { Number of dip or } \\
\text { spray at 20wt.\% }\end{array}$ & $\begin{array}{l}\text { Number of dip or } \\
\text { spray at 10 wt.\% }\end{array}$ \\
\hline DC 1 & 4 & 0 \\
DC 2 & 6 & 0 \\
SC 1 & 4 & 0 \\
SC 2 & 2 & 4 \\
SC 3 & 4 & 2 \\
DC 3 & 4 & 2 \\
DC 4 & 2 & 4 \\
\hline
\end{tabular}

addition, images with high field depth of the specimen surface are performed using a numerical microscope.

\subsection{Cyclic oxidation tests}

Cyclic oxidation tests are performed in a specific dedicated automated rig instrumented with CCD camera to monitor in a real time basis the evolution of the specimen surface during the air-forced $5 \mathrm{~min}$ cooling following the various cumulated $5 \mathrm{~min}$ heating plus 1 -h holding at $1100^{\circ} \mathrm{C}$ and at $1150{ }^{\circ} \mathrm{C}$. Individual $\mathrm{CCD}$ images are extracted from the video recording to be treated using image analysis software. From those " in-situ"experimental data, the surface fraction of cracks is derived as a function of time following each cycle to approach the overall surface damage kinetics.

\section{Results and discussion}

\subsection{Reinforcement of thermal barriers synthesized by sol-gel route}

The principle of TBC reinforcement is based on the deliberate establishment of a controlled micro-crack network throughout the entire coating deposited by the sol- getechnique. As indicated above, the formation of such cracks is inherent to the deposition process itself, but its geometrical characteristic is directly relative to the parameters used during the sol- geprocessing. As a matter of fact, the control of the micro-crack depth and space distribution can be achieved using well-defined process parameters, e.g. the number of dip-coating passes that keeps constant, the TBC thickness, and the time and temperature of heat treatment that determine the extent of sintering, namely in terms of densification and residual stress. Once the crack network is regularly formed, filling of the crack grooves using either dip-coating or spray-coating can be beneficially used to stiffen and strengthen the deposit so as to improve the resistance to cyclic oxidation.

Fig. 2a shows the profile of the outer surface of a TBC initially deposited by 4 successive dip-coating passes and heat treated for
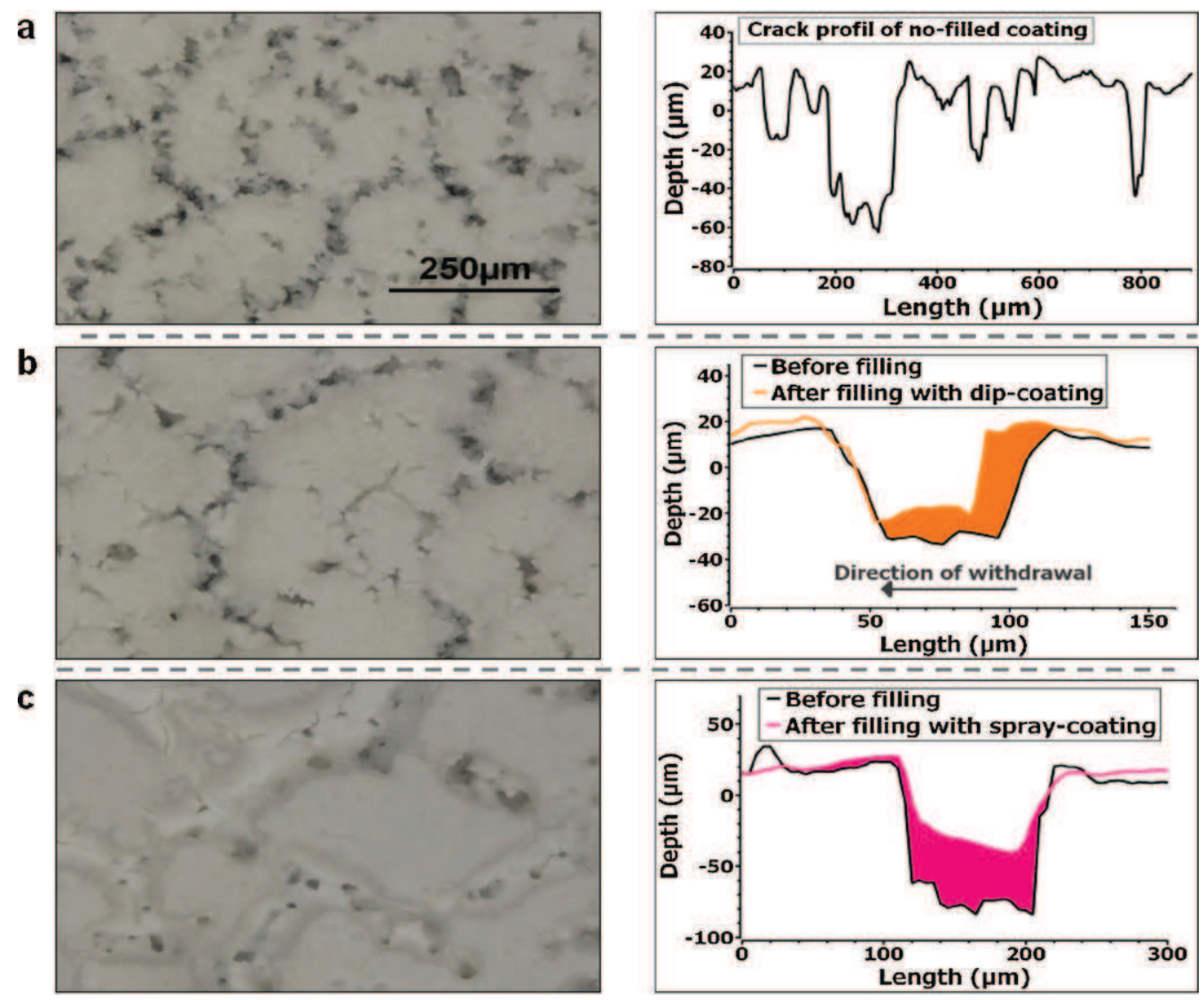

Fig. 2. Microstructure and cross-section profile of cracks of (a) the initial TBC, (b) the TBC reinforced using dip-coating process, and (c) the TBC reinforced using spray-coating process. 
Table 2

Surface and depth filling rates for specimen with various process parameters

\begin{tabular}{lcc}
\hline Filling of sample & $\Delta D / D(\%)$ & $\Delta S / S(\%)$ \\
\hline DC 1 & 14 & 35 \\
SC 1 & 44 & 45 \\
SC 2 & 44 & 53 \\
DC 4 & 12 & 37 \\
DC 3 & 7 & 47 \\
\hline
\end{tabular}

$2 \mathrm{~h}$ at $1100^{\circ} \mathrm{C}$. The profile is characterised by a rather regular distribution of cracks with various depth and width. Fig. $2 b$ and c presents details of an individual crack respectively filled by dip-coating and spray-coating, where the grey-coloured zones correspond to the filled parts where material, brought up by either dip or spray-coating, penetrates the crack, then solidifies and sinters as the consequence of post-processing heating. Both processes are quite efficient for plugging up cracks but, as clearly shown in Fig. 2, the quality of filling is highly process dependent. Unidirectional dip-coating based on axial withdrawal of specimens, results in a heterogeneous, non-symmetric filling, while spray-coating, deposited from the top and along a direction globally normal to the specimen, results in a homogeneous and symmetric filling.

To quantify process efficiency, the surface $(\Delta S / S)$ (respectively depth $(\Delta D / D))$ filling rates are determined by estimating the ratio between the increment in crack surface DS (respectively depth DD) after filling and the initial surface $S$ (respectively depth $D$ ) before filling.

It is interesting to note that the surface and depth filling rates are both higher for specimens treated by spray-coating, indicating a better filling efficiency for this process (Table 2). In addition, the difference of filling, beneficial to the spray-coating technique, is much more pronounced for the depth filling rate than for the surface filling rate. This unambiguously remark confirms the low capability of dip-coating to satisfactorily wet the bottom of the crack grooves.

As a consequence of this variation in the homogeneity and in the symmetry of the YSZ fillings, the distribution and magnitude of stress in the reinforced deposit are likely to be process dependent also. Resulting from these different initial conditions, the evolution of thermo-mechanical stresses due to cumulated oxidation cycles is expected to be different, leading to different thermo-mechanical behaviour. The oxidation durability of specimens, respectively reinforced using dip-coating and spraycoating is investigated in the next section.

A simple way to improve surface and depth filling rates could be done by increasing the amount of material brought up by additional deposition. So, to investigate the microstructural possible benefits, the number of passes has been increased by dip-coating technique, from four to six. The 3D profilometry image of a typical $100 \mu \mathrm{m}$ thick TBC deposited by ten successive initial dip-coatings and heat-treated at $1100^{\circ} \mathrm{C}$ is shown in Fig. 3a. The resulting 2D profiles and 3D map of the TBC after six supplementary dip-coating passes using a slurry with $20 \mathrm{wt} . \%$ YSZ are given respectively in Fig. $3 \mathrm{~b}$ and c. An additional cracks formation, revealed on the very top surface of TBC by the $3 \mathrm{D}$ profile map (Fig. 3c), clearly indicates that sintering has occurred during the post-filing heat treatment. It is also evidenced that new material has been brought up during filling, not only inside the cracks but also on top of the external surface of the barrier. In addition to penetrate crack grooves, further filling beyond four passes tend to favour the development of an over-layer whose thickness can be estimated by measuring the depth of sintering-induced cracks (Fig. 3b). Typically, the thickness of the overlayer resulting from 6 passes is about $30 \mu \mathrm{m}$ (note that it is only $2-5 \mathrm{~mm}$ for four passes). ${ }^{5}$ The propensity to spallation of over-filled sol- gel TBCs during cyclic oxidation is clearly shown and discussed in the paper. ${ }^{5}$ In this case, following four filling passes, the cyclic oxidation behaviour significantly improves, while following eight filling passes, it is very similar to that of the non-filled as processed TBC. This suggests that below a threshold number of passes, typically four with $20 \mathrm{wt} . \%$ of powder in slurry, the prevalent result remains the optimum filling of cracks and could lead to a beneficial strengthening of the reinforced TBC. Beyond this threshold, the overspreading prevails and almost no further filling of cracks occurs. This drastically increases the overall thickness of the TBC at the expense of a satisfactory filling of the cracks. Instead of reducing their depth, existing cracks further deepen and additional new cracks form, which somewhat results in a return back to the initial poorly adherent microstructure.

An attractive way to improve the efficiency of the crack filling process consists in adjusting the viscosity of the slurry by modifying the weight percent of powder depending on the considered pass. Initial (respectively final) passes can be performed using high weight percent (20 wt.\%), high viscosity (respectively low weight percent (10 wt.\%), low viscosity) slurry to fill in the largest (respectively the smallest) cracks. In such a way, the formation of the detrimental over-layer can be avoided while the overall stiffness and the mechanical strength of the TBC are enhanced. Examples of optimised crack filling are given in Fig. 4 for two specimens, filled in with six passes with two different viscosities of slurry (SC 2 and DC 5 as referenced in Table 2). It is shown that whatever the filling process, i.e. spray-coating or dip-coating, all cracks are at least partially filled as indicated by the grey-coloured areas separating the profiles before and after filling. In addition, note that no large over-thickness, prone to degrade mechanical resistance of the TBC, is observed. This is particular true for the TBC filled using spray-coating.

\subsection{Cyclic oxidation of reinforced thermal barrier coatings}

To estimate the efficiency of sol- gethermal barrier coating reinforced by filling of the micro-cracks network, oxidation tests have been performed on the fully automated cyclic oxidation rig described in Section 2.3. Coating damage resulting from the successive cooling sequences of the cumulated oxidation cycles is monitored in situ to derive the degradation kinetics of the TBC.

First, the oxidation behaviour of two specimens reinforced respectively using dip-coating and spray-coating is compared. This allows to address in terms of resistance to cyclic oxidation the advantages and drawbacks of the two filling techniques, 


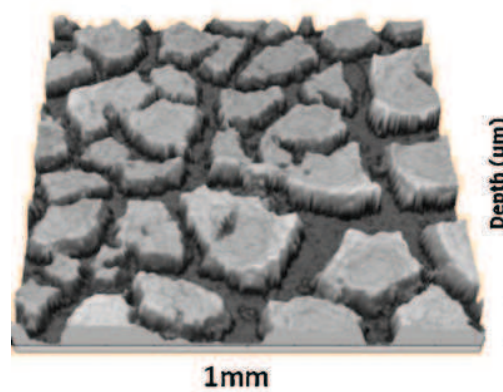

a. Before filling

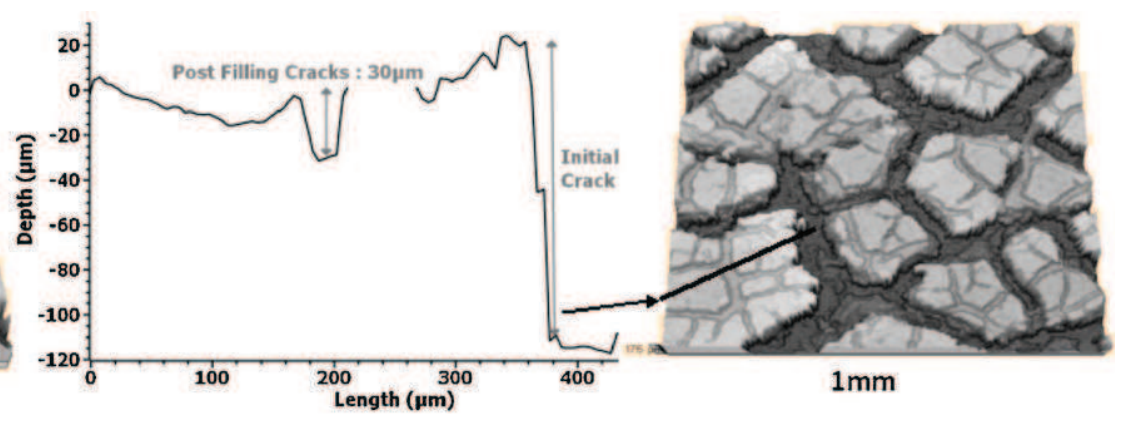

b. Cracks profile c. Following 6 Dip-coating (DC 3)

Fig. 3. Morphology of the TBC surface (a) as-processed, before filling, (b) cracks profile of the surface represented by line shown in c, (c) following 6 dip-coatings (DC 3).
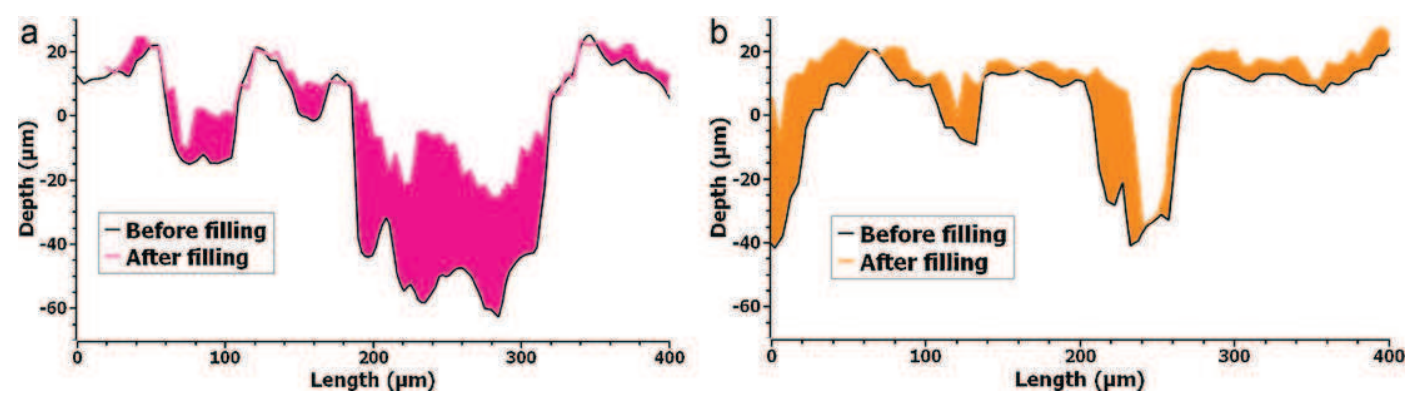

Fig. 4. Crack profiles of specimens filled using (a) spray-coating (SC 2) and (b) dip-coating (DC 3).

each leading to a specific microstructure, either directional and asymmetric for dip-coating and homogeneous and symmetric for spray-coating. Then, the specific damage mechanisms of spray-coating reinforcements will be discussed by investigating the impact of different material-intrinsic parameters, i.e. the number of passes and the weight percent of powder in the slurry, and material-extrinsic parameters, i.e. the number of oxidation cycles and the oxidation temperature.

\subsection{Cyclic oxidation resistance: dip- coatingversus spray-coatingreinforcement}

Fig. 5a compares the initial surface and surface evolution of spray-coated (left column) and dip-coated (right column) filled TBCs during cumulative one-h oxidation cycles at $1100^{\circ} \mathrm{C}$, i.e. before oxidation (i), following 50 one-h oxidation cycles at $1100{ }^{\circ} \mathrm{C}$ (ii), and following 100 one-h oxidation cycles at
$1100{ }^{\circ} \mathrm{C}$ (iii). The aspect of the surface prior to oxidation is quite different as cracks are clearly observed in the case of the dip-coated TBC while only ridges, delineating the initial sintering-induced cracks, are on the spray-coated TBC. This confirms the limited capability of dip-coating to achieve satisfactory filling of crack grooves, due to the use of directional filling process. The surface morphology of the spray-coated TBC does not progress following either 50 or 100 oxidation cycles as no evolution of the ridges network occurs confirming the remarkable efficiency of the TBC mechanical strengthening.

For the dip-coating reinforced TBC, oxidation damage takes place through the percolation of the initial crack network coupled to an extensive widening of the cracks.

In both cases, the surface fraction of cracks, estimated by image analysis of room temperature micrographs extracted from the video tape recording following successive completed cooling sequences, is plotted as a function of the number of oxidation

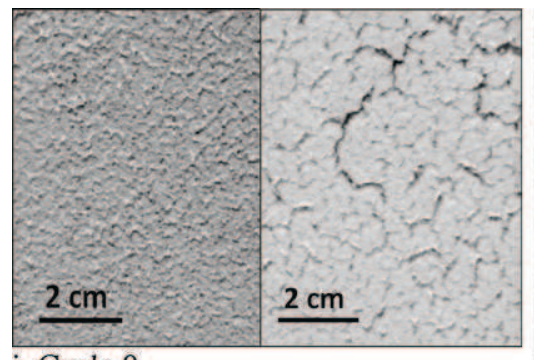

i. Cycle 0

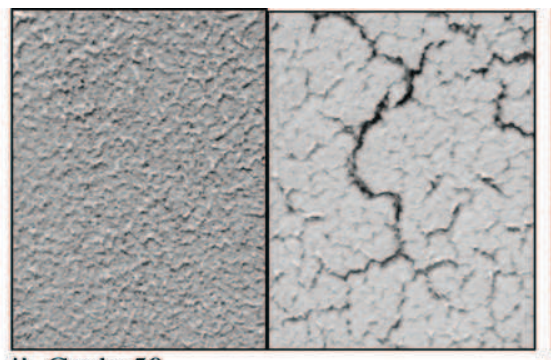

ii. Cycle 50

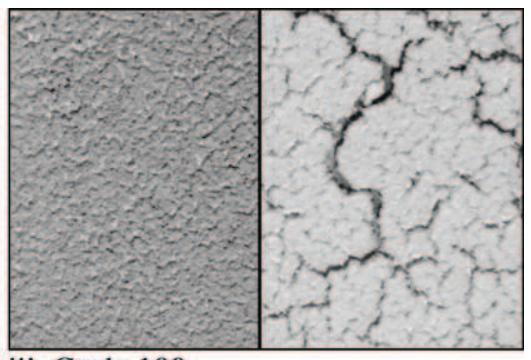

iii. Cycle 100

Fig. 5. Surface of TBC reinforced with spray-coating SC 3 (left column) and with dip-coating DC 4 (right column) during the cooling (5 min) after one-h oxidation cycles at $1100^{\circ} \mathrm{C}$. 


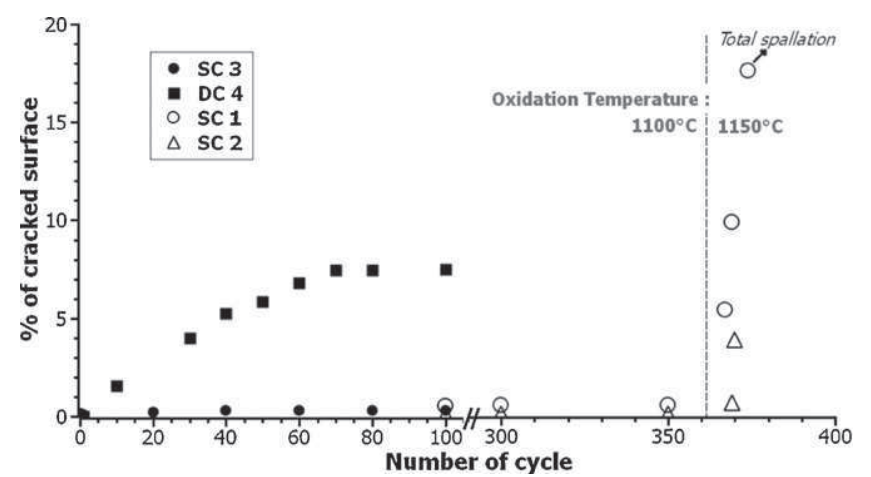

Fig. 6. Evolution of the surface fraction of crack versus the number of one-h oxidation cycles.

cycles in Fig. 6 (black circles and squares). Monitoring the surface fraction of cracks, which is the difference between the fraction before oxidation (cycle 0) and the fraction after oxidation (cycle 10- 100)allows to accurately determine the extent of additional cracking resulting from each individual cycle. For the dip-coated reinforced TBC, the surface fraction of cracks rapidly increases during the very first cycles to reach $7.5 \%$ at 70 cycles and then stabilises from 70 to 100 cycles. Note that for the spray-coated reinforced $\mathrm{TBC}$, the surface fraction of crack remains lower than $1 \%$ up to 100 cycles. The higher resistance to crack coalescence and enlargement of the spray-coat reinforced $\mathrm{TBC}$ is essentially due to the higher amount of material that fills the crack network and the better homogeneous distribution of materials within the cracks. This process specificity undoubtedly minimizes the extent and homogenizes the distribution of residual stress resulting from the post-filling heat treatment.

In the next section, spray-coated reinforced TBCs filled using various parameters, namely the sequence of filling and the weight percent of YSZ in the slurry for each passes, are thermally cycled at both $1100{ }^{\circ} \mathrm{C}$ and $1150^{\circ} \mathrm{C}$ to finally propose an optimised processing route regarding cyclic oxidation performance.

\subsection{The influence of process parameters and test conditions on the cyclic oxidation resistance of spray-coatTBCs}

Fig. 7 details the microstructural behaviour of spray-coated reinforced TBCs subject to 350 oxidation cycles at $1100^{\circ} \mathrm{C}$ (Fig. 7a), followed by 22 additional oxidation cycles at $1150{ }^{\circ} \mathrm{C}$ (Fig. 7b). On the left hand side column (respectively the right hand side column), is reported the evolution of the surface degradation for a TBC reinforced by two successive fillings with a $20 \mathrm{wt} . \%$ YSZ slurry plus four fillings with a $10 \mathrm{wt}$.\% YSZ slurry (respectively four successive fillings with a $20 \mathrm{wt} . \%$ YSZ slurry). Namely the surface of the reinforced TBCs before oxidation (i), following 150 one-h oxidation cycles at $1100^{\circ} \mathrm{C}$ (ii), following 350 one-h oxidation cycles at $1100{ }^{\circ} \mathrm{C}$ (iii), following 350 one-h oxidation cycles at $1100^{\circ} \mathrm{C}$ plus 15 one-h oxidation cycles at $1150{ }^{\circ} \mathrm{C}$ and before (iv) and just after (v) the $372 \mathrm{nd}$ one-h oxidation cycles $\left(350\right.$ cycles at $1100{ }^{\circ} \mathrm{C}$ plus 22 oxidation cycles at $1150{ }^{\circ} \mathrm{C}$ ) are presented.
For both spray-coat filling routes, oxidation at $1100^{\circ} \mathrm{C}$ does not degrade the surface as the typical ridged microstructure present no cracking or spallation up to 350 cycles. Fig. 6 reports the surface fraction of crack versus the number of cycles (white circles and triangles) that remains lower than $1 \%$ up to 350 cycles. In order to enhance oxidation damage, the oxidation temperature is increased to $1150^{\circ} \mathrm{C}$ from the 360th cycle. Such a high oxidation temperature accelerates both the sintering of zirconia and the growth of the alumina thermally grown oxide (TGO). This results in a rapid and extended surface damage through crack coalescence and enlargement, giving rise to a sudden increase of the cracks surface percent value in Fig. 6, typical of breakaway oxidation. For the TBCs filled using 6 spray-coatings with two different slurry viscosities, the surface fraction of cracks remains however low and no spallation is observed. Conversely, for the TBCs reinforced using four spraycoatings and only one slurry viscosity, degradation is much more pronounced and ends up, right after the 372 nd cycle, by a complete spallation of the whole barrier, as indicated by the very last white circle in the graph in Fig. 6 and the image in Fig. 7b (v). The higher strength of the TBCs reinforced by slurry with appropriate viscosity is related to the optimum filling of cracks with different sizes, promoting a better homogeneity of the surface subjected to oxidation cycles.

The cyclic oxidation behaviour of reinforced TBCs is quite different to that of sol- gelas-processed TBCs, where cracking and subsequent spallation are progressive as cracks first coalesce to finally delineate individual YSZ cells prone to local delamination. ${ }^{8,9}$ An attempt is made to model the mechanisms of YSZ detachment from the substrate surface during the oxidation cycles and differentiate the behaviour of non-reinforced (Fig. 8a) and reinforced TBCs (Fig. 8b). For as-processed, non-reinforced TBCs, horizontal failure initiates at the bottom of the vertical sintering-induced cracks as the result of the thermo-mechanical stresses due to cumulative oxidation cycles. Once formed, such a horizontal crack propagates parallel to the interface between the substrate and the barrier. As the crack fully crosses the width of an elementary zirconia cell, the barrier looses its adherence to the bond coat and detaches in the form of an individual spall (Fig. 8a). Damage can further enhance through the spallation of supplementary zirconia cells as the oxidation cycling progresses and additional cracks develop.

The reinforcement by spray-coat filling of the initial cracks allows the consolidation of TBCs by providing strong bonding between the individual zirconia cells, which delays the initiation of horizontal failure. Because of the stiff bridging that occurs as the result of filling, the horizontal cracks, once initiated, propagate roughly at the interface between the substrate and the barrier without any individual spall off. The cracks have to propagate throughout the entire interface before leading to the complete spallation of the TBC (Fig. 8b). This sudden and total spallation of sol- geteinforced TBCs is very similar to that observed typically in EB-PVD TBCs as extensively reported in the literature. ${ }^{12-14}$

The failure of sol- gereinforced TBC is as complex as the one of EB-PVD barriers on Pt-aluminised system, where the fracture may either locate at the interface between the TGO and 


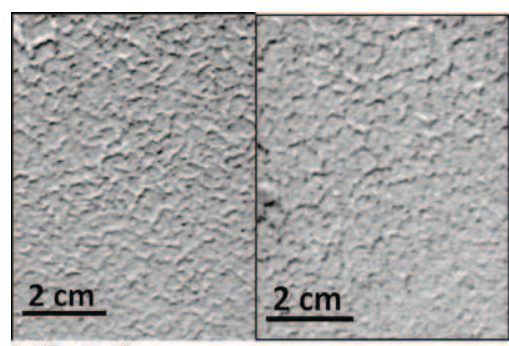

i. Cycle 0

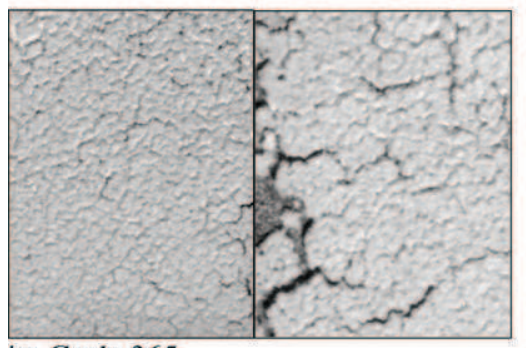

iv. Cycle 365

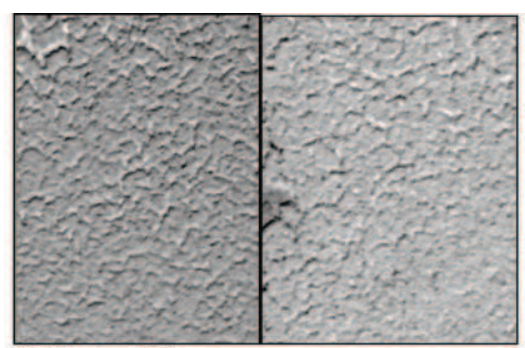

ii. Cycle 150

a. oxidation temperature $: 1100^{\circ} \mathrm{C}$

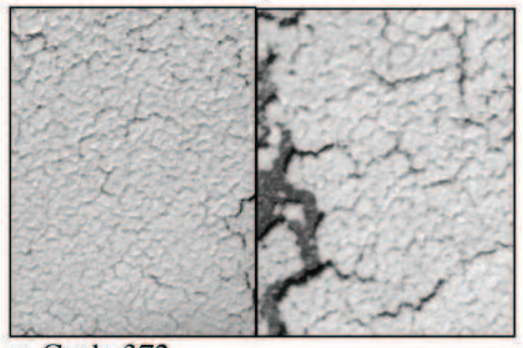

v. Cycle 372

b. oxidation temperature : $1150^{\circ} \mathrm{C}$

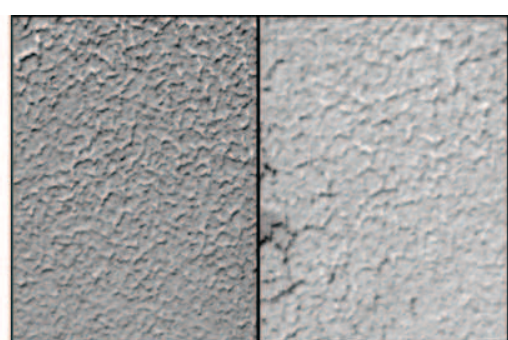

iii. Cycle 350

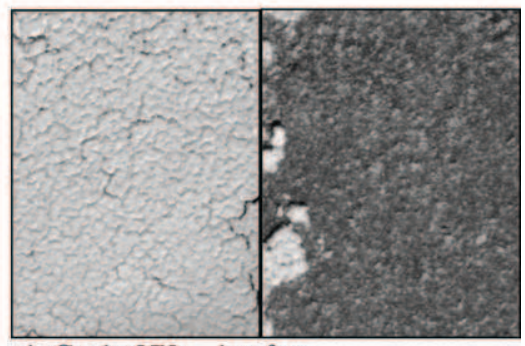

vi. Cycle $372-1$ s after

Fig. 7. Surface of TBC reinforced with optimised spray-coating (SC 2) (left column) and non optimised spray-coating (SC 1) (right column) during the cooling (5 min) after one-h oxidation cycles at $1100^{\circ} \mathrm{C}$ (a) and one-h oxidation cycles at $1100^{\circ} \mathrm{C}$ plus one-h oxidation cycles at $1150^{\circ} \mathrm{C}(\mathrm{b})$.
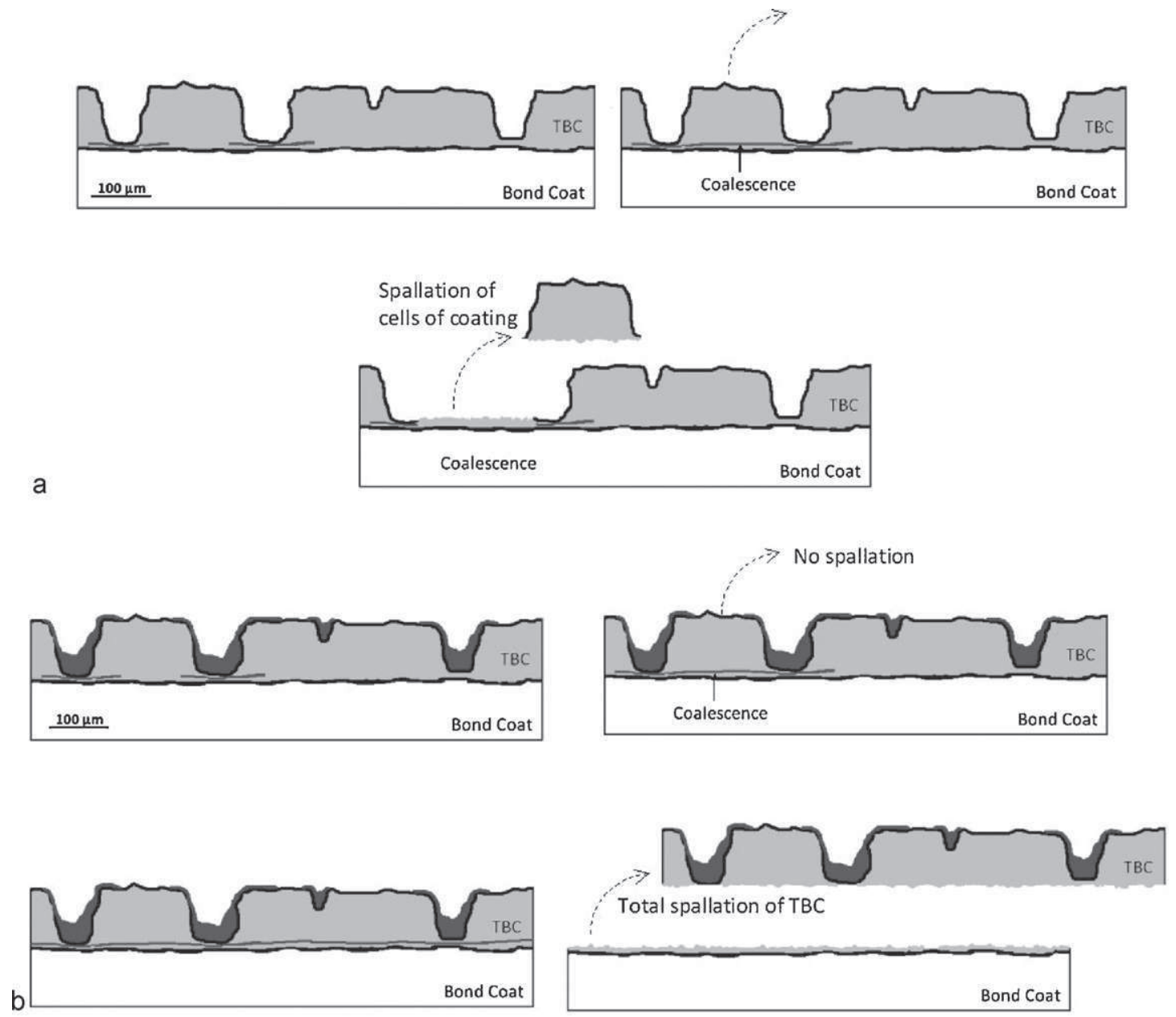

Fig. 8. Mechanism of oxidation damage of (a) as-processed, non-reinforced sol- ge ГВС, and (b) reinforced sol- geГВС. 


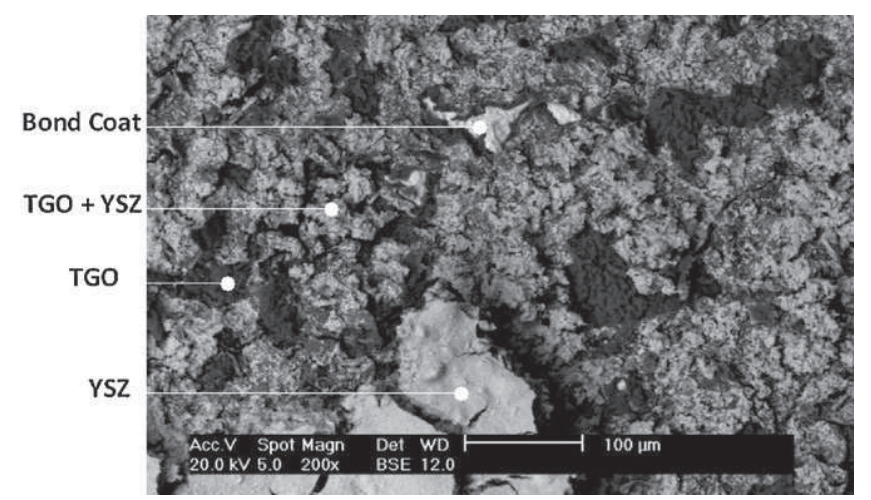

Fig. 9. SEM micrograph of sol- gelTBC reinforced with spray-coating (SC $3)$ after 372 one-h oxidation cycles $\left(350\right.$ cycles at $1100^{\circ} \mathrm{C}$ plus 22 cycles at $\left.1150^{\circ} \mathrm{C}\right)$.

the bond coat ${ }^{15}$ or between the TGO and the TBC. ${ }^{16}$ In sol- gel $\mathrm{TBC}$, the crack path responsible for the spallation is alternatively adhesive, resulting in a detachment at the interface between the bond-coat and the TGO or at the interface between the TGO and the YSZ, or cohesive, leading to the spallation inside the YSZ coating. This is illustrated in Fig. 9, where the SEM micrograph of the external surface of a coating reinforced by two successive spray-coat fillings with a $20 \mathrm{wt} . \%$ YSZ slurry added by four spray-coat fillings with a $10 \mathrm{wt} . \%$ YSZ slurry after 372 oxidation cycles $\left(350\right.$ at $1100{ }^{\circ} \mathrm{C}$ and 22 at $1150{ }^{\circ} \mathrm{C}$ ) is presented. Note that the main failure is located within the YSZ sol- gekoating over the TGO, which suggests a good adherence of the coating to the substrate.

\section{Conclusion}

Sol- gelthermal barrier coatings are intrinsically microcracked as the manufacturing process includes a heat treatment resulting in the sintering of the yttria-stabilized zirconia. The occurrence of this crack network has the main advantage to release residual stresses and stabilize the TBC. However, this specific microstructure alone shows poor resistance to cyclic oxidation and needs to be reinforced prior to long-term high temperature exposure. The feasibility of consolidating sol- gel TBCs by filling the process-induced crack grooves by additional YSZ material brought up either by dip-coating or spray-coating, has been addressed. The parameters used to properly conduct the filling process have been optimised, regarding mainly the cyclic oxidation resistance of reinforced TBC. The main results are listed below.

- The dip-coating method, consisting in withdrawing substrate to be coated from a slurry, is essentially directional and results in a non-symmetric filling of crack, while the filling by the spray-coating method is homogeneous.

- The spray-coating technique, consisting in spraying uniformly YSZ, results in a more efficient and a more homogeneous filling of cracks,
- Spray-coated reinforced TBCs show longer cyclic oxidation life than dip-coated reinforced TBCs as a result of their more uniform microstructure with lower residual stresses,

- The filling efficiency can be optimised by a proper adjustment of the process parameters, namely the viscosity of the slurry that must be changed as a function of the size of cracks to be filled in,

- Optimised reinforced TBCs shows a high resistance to oxidation cycling as almost no cracks and no spallation occur within 350 one-h cycles at $1100^{\circ} \mathrm{C}$,

- Increasing oxidation temperature from $1100^{\circ} \mathrm{C}$ to $1150^{\circ} \mathrm{C}$ dramatically enhances the degradation of the TBCs that may fail by total spallation (non optimised reinforcement) or by detrimental crack enlargement (optimised reinforcement),

- Failure of the optimised spray-coated reinforced TBC during thermal cycling mainly occurs within the YSZ, suggesting a fairly good adhesion of the deposit on top of the bond coat.

\section{References}

1. Nicholls JR, Lawson KJ, Johnstone A, Rickerby DS. Methods to reduce the thermal conductivity of EB-PVD TBCs. Surf Coat Technol 2002;151-152:383- 91.

2. Fenech J, Dalbin M, Barnabe A, Bonino JP, Ansart F. Sol- geprocessing and characterization of (RE-Y)-zirconia powders for thermal barrier coatings. Powder Technol 2011;208:480- 7.

3. Clarke DR, Phillpot SR. Thermal barrier coating materials. Mater Today 2005;8:22- 9 .

4. Cao XQ. Application of rare earths in thermal barrier coating materials. $J$ Mater Sci Technol 2007;23:15- 35.

5. Wang X, Lan WH, Xiao P. Fabrication of yttria stabilized zirconia coatings by a novel slurry method. Thin Solid Films 2006;494:263- 7.

6. Ren C, He YD, Wang DR. Cyclic oxidation behavior and thermal barrier effect of YSZ- $\left(\mathrm{A}_{2} \mathrm{O}_{3} / \mathrm{YAG}\right)$ double-layer TBCs prepared by the composite sol- gemethod. Surf Coat Technol 2011;206:1461- 8.

7. Viazzi C, Bonino JP, Ansart F. Synthesis by sol- geroute and characterization of yttria stabilized zirconia coatings for thermal barrier applications. Surf Coat Technol 2006;201:3889- 93.

8. Sniezewski J, LeMaoult Y, Lours P, Pin L, Bekale VM, Monceau D, et al. Sol- gethermal barrier coatings: optimization of the manufacturing route and durability under cyclic oxidation. Surf Coat Technol 2010;205:1256- 61.

9. Pin L, Ansart F, Bonino J-P, Maoult YL, Vidal V, Lours P. Processing, repairing and cyclic oxidation behaviour of sol- gethermal barrier coatings. Surf Coat Technol 2011;206:1609- 14.

10. Shane M, Mecartney ML. Sol- gekynthesis of zirconia barrier coating. $J$ Mater Sci 1990;25:1537- 44.

11. Fenech J, Viazzi C, Bonino J-P, Ansart F, Barnabé A. Morphology and structure of YSZ powders: comparison between xerogel and aerogel. Ceram Int 2009;35:3427- 33.

12. Tolpygo VK, et al. Morphological evolution of thermal barrier coatings induced by cyclic oxidation. Surf Coat Technol 2003;163-164:81- 6 .

13. Mumm DR, Evans AG, Spitsberg IT. Characterization of a cyclic displacement instability for a thermally grown oxide in a thermal barrier system. Acta Mater 2001;49:2329- 40.

14. Tolpygo VK, Clarke DR, Murphy KS. Oxidation-induced failure of EB-PVD thermal barrier coatings. Surf Coat Technol 2001;146-147:124- 31.

15. Vande-Put A, Oquab D, Monceau D. Characterization of TBC systems with $\mathrm{NiPtAl}$ or NiCoCrAlYTa bond coatings after thermal cycling at $1100^{\circ} \mathrm{C}$ : a comparative study of failure mechanisms. Mater Sci Forum 2008:213- 21.

16. Tolpygo VK, Clarke DR. Surface rumpling of a (Ni,Pt)Al bond coat induced by cyclic oxidation. Acta Mater 2000;48:3283- 93. 